\title{
The Impact of a Letter of Map Amendment on Floodplain Property Value
}

\author{
James E. Larsen \\ Department of Finance and Financial Services, \\ Raj Soin College of Business, Wright State University, Dayton, OH, USA
}

\begin{abstract}
Substantial empirical evidence indicates properties across the United States that are located within a Special Flood Hazard Area (SFHA) sell at a discount compared to similar properties otherwise located. This result is also true in our sample. Researchers have suggested the price discount equals a combination of the present value of the required flood insurance premiums and the value of uninsurable costs. To identify the portion of the discount applicable to each component, analysts have been required to estimate applicable insurance premiums and to assume a discount rate. The present paper presents a methodology that does not require these prerequisites, but still enables separation of the discount into the two components. in the united states, the federal emergency management agency sometimes issues a Letter of Map Amendment (LOMA), which exempts a property from the requirement that it be insured against flood damage as a prerequisite to the owner obtaining a federally-related mortgage loan. Therefore, any price difference between non-LOMA SFHA properties and similar properties outside the SFHA should continue to equal the sum of the two components and any significant price difference between SFHA properties with a LOMA and similar properties located outside the SFHA should equal the present value of the uninsurable costs only. Hedonic regression is used to test this proposal by comparing the selling prices of single-family house transactions for properties located within and outside the SFHA in Kettering, Ohio. In our sample, no significant uninsurable costs were detected.
\end{abstract}

Keywords: FEMA, Floodplain, Letter of Map Amendment (LOMA), Hedonic Regression Analysis, Single-Family House Value

\section{INTRODUCTION}

Floods constitute a significant hazard to life and property worldwide. In the United States floods are one of the most commonly occurring and widespread natural disasters (Perry, 2000), but in the past flooding risks were often minimized or ignored by both local governments and floodplain residents until a flood occurred and adverse selection problems prevented private insurers from offering policies to cover flood damage. These circumstances led to passage of The National Flood Insurance Act of 1968 (Act) which, in part, provided for federal government subsidized flood insurance policies. The Federal Emergency Management Agency (FEMA), which administers the National Flood Insurance Program, has issued Flood Insurance Rate
Maps (FIRMs) for thousands of communities nationwide and for over 700 communities in Ohio. Among other things, a FIRM identifies the 100 year floodplain which is termed the Special Flood Hazard Area (SFHA). The Act requires that purchasers of an improved parcel in a SFHA have a flood insurance policy in place before a lender originates a mortgage loan on the property. There are, however, actions that some affected property owners may take to avoid this requirement. One of these actions is to secure from FEMA a letter of Map Amendment (LOMA). Issuance of a LOMA does not remove the property from the SFHA, but it does remove the requirement to obtain flood insurance.

With required flood insurance, risk neutral or riskaverse individuals contemplating the purchase of a home in a SFHA should demand price concessions at least 
equal to the present value of both the flood insurance policy premiums and the value of any uninsurable costs (e.g., value of time spent taking inventory of the damage, hiring contractors, replacing damaged items, making temporary repairs, as well as nonpecuniary costs such as psychological costs, loss of sentimental items and any property damage over policy limits). There is ample empirical evidence that single-family houses in high-risk flood zones sell for significantly less than similar houses not so situated. A number of researchers have concluded that the price discount associated with floodplain properties was greater than the present value of annual flood insurance premiums (MacDonald et al., 1990; Speyrer and Ragas, 1991; Harrison et al., 2001; Bin and Polasky, 2004; Bin et al., 2008). Discounts that exceed the capitalized value of future flood insurance premiums suggest that non-insurable costs associated with flooding existed in the study markets. Segregating the total price discount into its two component parts in previous studies was a cumbersome process which required researchers to estimate both the applicable flood policy premiums and capitalization rate. In the present study an alternative methodology which does not require these estimates is introduced.

This study reports the first empirical investigation of the impact of a LOMA on the value of single-family houses in a SFHA. To accomplish this objective hedonic regression is employed to analyze data from 6,233 transactions that occurred between 1988 and 2011 in Kettering, Ohio. The transaction price of single-family houses located outside the SFHA is simultaneously compared to the price of single-family houses located in the SFHA with a LOMA and to the price of houses in the SFHA without a LOMA. Consistent with previous research, the results indicate that houses in the SFHA without a LOMA sell, on average, at a discount of $2.84 \%$ compared to similar properties located outside the SFHA, but no significant price difference is discovered between houses located outside the SFHA and those inside the SFHA with a LOMA. These findings indicate two things: (1) that the issuance of a LOMA successfully increases the selling price of the subject property and (2) that uninsurable costs were insignificant in our sample.

\section{MATERIALS AND METHODS}

\subsection{Data}

The study area is the City of Kettering which is located the southeastern corner of Montgomery County, Ohio. Montgomery County is situated within the Miami River Watershed in the southwestern corner of the state and is characterized by flat to gently rolling terrain underlain by glacial till and rich soils. Four major rivers basins run into the Great Miami River in Montgomery County; the Mad River, the Stillwater River, Wolf Creek and Twin Creek. According to the 2010 Census, Kettering is the second most populace city in Montgomery County with a population of 56,163 (down $2.3 \%$ from the 2000 population of 57,502 ) and it covers 18.7 square miles. In 2009 , it had 25,675 housing units, $66.5 \%(17,082)$ of which were owner-occupied.

Historically, the primary weather-related risk in Montgomery County has been flooding; the worst of which occurred a century ago in Dayton (the County seat). In March, 1913, heavy rains caused a catastrophic flood. More than 400 people died and property damage amounted to $\$ 1.8$ billion. After the 1913 flood, the Miami Conservancy District and the Army Corps of Engineers constructed earthen dams along tributaries, widened and increased the height of banks of the Great Miami River and created retarding basins to help prevent flooding. No major flooding has occurred in the area since the completion of these flood mitigation efforts. The last flood in the area which resulted in a Presidential disaster declaration occurred in 1989 and caused \$4.3 million in damage. Only seven local flooding events have occurred since 1989, the worst of which caused only $\$ 228,400$ in reported damage. Given this history, it would be understandable if local residents tended to underestimate the potential detrimental effects of flooding.

We focus this study on Kettering primarily because of data availability; it is the only jurisdiction within the County that has enough transactions of single-family houses in the SHFA with a LOMA to yield statistically reliable results. According to Hooker (2004), all of Montgomery County had 4,447 structures in the Special Flood Hazard Area (SFHA). Kettering has 774 structures in the SFHA, more than any other jurisdiction in the county. An additional benefit of limiting the study area is that the need to include numerous additional variables in the model to control for the less homogenous nature of a wider geographical area is avoided.

Data for the study was compiled from a variety of sources. Property characteristic and transaction data for all single-family house transactions that occurred in the City of Kettering between January 1998 and March 2011, inclusive, were obtained from the Montgomery County, Ohio Auditor's Office. Usable data was available for 6,233 transactions. Because floodplain status is not in the Auditor's records, personnel at the Center for Urban and Public Affairs at Wright State University were employed to determine whether each property in the auditor's data base was located in or out of the SFHA. This was accomplished by matching the parcel identification number in the research data to flood maps obtained from FEMA. For transactions that 
occurred since January 6, 2005, the current maps (which became effective on that date) were used. For transactions that occurred prior to January 6, 2005, the map that was in effect from October 15, 1980 through January 5, 2005 was used. The results of this process indicate that 323 of the transactions in the larger data base involved single-family houses in the SFHA.

Two sources were used to identify parcels in the SFHA containing a single-family house for which a LOMA had been issued. Hard copy document files at the City of Kettering Office of Engineering were searched and electronic files at the FEMA Map Service Center Internet site were examined. The results of these efforts indicated that FEMA issued a LOMA for 75 parcels in the city containing a single-family house between September 12, 1984 and December 31, 2009. A comparison of the LOMA issuance date for each parcel with parcel transaction dates revealed that 35 transactions involved single-family houses where a LOMA had been issued prior to the transaction. Our final sample, therefore, contains 35 transactions for parcels in the SFHA with a LOMA, 288 transactions for parcels in the SFHA with no LOMA and 5,910 transactions where the parcel was outside the SFHA.

Summary statistics of the variables in the data base for each of these three parcel categories are presented in Table 1-3 Casual observation of these tables will reveal that, on average, houses in the SFHA with a LOMA are approximately ten years younger than houses in the other two categories. In addition, compared to houses in the other two categories, a smaller proportion of houses with a LOMA have a full basement. It is also apparent that houses in the SFHA without a LOMA tend to have fewer desirable amenities (e.g., less bedrooms, smaller lot size) compared to houses in the other categories.

\subsection{Letter of Map Amendment (LOMA)}

As mentioned in the Introduction, the National Flood Insurance Act of 1968 mandates flood insurance as a prerequisite to obtaining a mortgage loan on a property in a SFHA and this requirement has been shown to reduce property value. FEMA has a procedure which enables some floodplain property owners to avoid this requirement. If the property owner provides FEMA with the appropriate evidence, FEMA will issue a Letter of Map Change (LOMC). There are two basic types of LOMC; one, a Letter of Map Revision (LOMR), is issued when FEMA has determined that a (normally man-made) change has occurred which affects the status of a property or properties (e.g., a parcel has been elevated by fill in its entirety above the Base Flood Elevation (BFE)). A LOMR is an official revision, by letter, to an effective National Flood Insurance Program map. A LOMR may change flood insurance risk zones, floodplain and/or floodway boundary delineations, planimetric features and/or the local BFE. Because a LOMR officially removes the subject property from the SFHA, the flood insurance requirement is also eliminated.

The second type of LOMC and the focus of our study, is a Letter of Map Amendment (LOMA). For a LOMA to be issued, FEMA regulations require, among other things, that the property owner submit evidence that the lowest adjacent grade (the lowest ground touching the structure) be at or above the BFE. The elevation information must be provided by a Certified Surveyor, a Registered Professional Engineer, or an architect who is authorized to certify elevation information. If FEMA approves the request, it issues a LOMA. The issuance of a LOMA does not change the SFHA boundary (a portion of the subject parcel remains officially in the SFHA), nor does it mean the structure or lot is safe from flooding. What it does mean is that FEMA is convinced that the risk of flooding is not as high for the structure on the subject parcel as it is for structures on other parcels in the SFHA. Most importantly, at least from the property owner's perspective, a LOMA exempts the parcel from the requirement that it be insured against flood damage as a prerequisite to the property owner obtaining a federallyrelated mortgage loan for the existing structure. Theoretically, a LOMA should eliminate any price discount associated with required flood insurance policy premiums. Determining whether this applies to LOMA properties in the study area is a major focus of the present study.

\subsection{The Model}

Hedonic regression, a technique that is well established in the literature for identifying the price impact of SFHA location, is employed here to simultaneously compare transaction prices of three groups of single-family houses: (1) those located outside the SFHA, (2) those located within the SFHA without a LOMA and (3) those located within the SFHA on which a LOMA had been issued previous to the transaction. Our objective is twofold. First, is to determine whether houses within the SFHA without a LOMA systematically sold at a significant discount from similar parcels located outside the SFHA. A priori, there is little reason to suspect that Kettering is different than any previously studied market in this regard. Our second objective is to determine if houses in the SFHA with a LOMA sell, ceteris paribus, at significantly different prices than properties outside the SFHA. We hypothesize that without required flood insurance, any portion of the discount for SFHA location attributable to the flood insurance policy premium will disappear for these properties, but a significant price difference may still obtain if significant uninsurable costs exist. 
Table 1. Summary property characteristics-houses with a LOMA

\begin{tabular}{|c|c|c|c|c|c|}
\hline Variable & Description & Mean & Std Dev & Minimum & Maximum \\
\hline$\overline{\text { PRICE }}$ & Sales price in dollars & $121,029.000$ & $33,147.000$ & $60,200.0$ & $192,000.0$ \\
\hline AGE & Structure age in years & 35.940 & 15.580 & 0.0 & 59.0 \\
\hline BED & Number of bedrooms & 3.140 & 0.550 & 2.0 & 5.0 \\
\hline BATH & Number of bathrooms & 1.800 & 0.660 & 1.0 & 3.5 \\
\hline SQFT & Sq. ft. of living space & $1,601.230$ & 557.710 & 960.0 & $2,923.0$ \\
\hline FIRE & Number of fireplaces & 0.460 & 0.510 & 0.0 & 1.0 \\
\hline LOT & Square feet in parcel & $11,843.980$ & $5,016.280$ & $4,400.0$ & $23,958.0$ \\
\hline COND & Property condition & 6.560 & 0.360 & 5.5 & 7.5 \\
\hline FALL & Sept.-Nov. transaction & 0.257 & 0.443 & 0.0 & 1.0 \\
\hline WINTER & Dec.-Feb. transaction & 0.200 & 0.406 & 0.0 & 1.0 \\
\hline SPRING & Mar.-May transaction & 0.229 & 0.426 & 0.0 & 1.0 \\
\hline BRICK & Brick or stone exterior & 0.429 & 0.502 & 0.0 & 1.0 \\
\hline AIR & Central air conditioning & 0.829 & 0.382 & 0.0 & 1.0 \\
\hline FULL & Full basement & 0.229 & 0.426 & 0.0 & 1.0 \\
\hline NONE & No basement & 0.714 & 0.458 & 0.0 & 1.0 \\
\hline OWN & Owner-occupied & 0.914 & 0.284 & 0.0 & 1.0 \\
\hline
\end{tabular}

Table 2. Summary property characteristics-houses in the SFHA without a LOMA

\begin{tabular}{|c|c|c|c|c|c|}
\hline Variable & Description & Mean & Std Dev & Minimum & Maximum \\
\hline$\overline{\text { PRICE }}$ & Sales price in dollars & $103,704.000$ & $50,785.000$ & $16,000.0$ & $555,000.0$ \\
\hline AGE & Structure age in years & 44.910 & 11.030 & 4.0 & 91.0 \\
\hline BED & Number of bedrooms & 2.960 & 0.650 & 1.0 & 5.0 \\
\hline BATH & Number of bathrooms & 1.440 & 0.530 & 1.0 & 3.5 \\
\hline SQFT & Sq. ft. of living space & $1,415.490$ & 668.430 & 684.0 & $6,170.0$ \\
\hline FIRE & Number of fireplace & 0.320 & 0.550 & 0.0 & 4.0 \\
\hline LOT & Square feet in parce & $19,940.760$ & $5,001.430$ & $4,400.0$ & $40,511.0$ \\
\hline COND & Property condition & 6.150 & 0.690 & 4.5 & 10.0 \\
\hline FALL & Sept.-Nov. transaction & 0.247 & 0.432 & 0.0 & 1.0 \\
\hline WINTER & Dec.-Feb. transaction & 0.153 & 0.360 & 0.0 & 1.0 \\
\hline SPRING & Mar.-May transaction & 0.264 & 0.442 & 0.0 & 1.0 \\
\hline BRICK & Brick or stone exterior & 0.378 & 0.486 & 0.0 & 1.0 \\
\hline AIR & Central air conditioning & 0.590 & 0.493 & 0.0 & 1.0 \\
\hline FULL & Full basement & 0.292 & 0.455 & 0.0 & 1.0 \\
\hline NONE & No basement & 0.639 & 0.481 & 0.0 & 1.0 \\
\hline OWN & Owner-occupied & 0.865 & 0.343 & 0.0 & 1.0 \\
\hline
\end{tabular}

$\mathrm{n}=288$

Table 3. Summary property characteristics-houses located outside the SFHA

\begin{tabular}{|c|c|c|c|c|c|}
\hline Variable & Description & Mean & Std Dev & Minimum & Maximum \\
\hline$\overline{\text { PRICE }}$ & Sales price & $127,966.00$ & $69,911.00$ & 7,550 & 920,000 \\
\hline AGE & Structure age in years & 45.81 & 13.78 & 0 & 172 \\
\hline BED & Number of bedrooms & 3.01 & 0.62 & 1 & 8 \\
\hline BATH & Number of bathrooms & 1.65 & 0.69 & 1 & 7 \\
\hline SQFT & Sq. ft. of living space & $1,685.43$ & 895.53 & 396 & 10,571 \\
\hline FIRE & Number of fireplaces & 0.54 & 0.69 & 0 & \\
\hline LOT & Square feet in parcel & $11,373.43$ & $8,031.40$ & 2,004 & 226,948 \\
\hline COND & Property condition & 6.58 & 0.78 & 3 & 10 \\
\hline FALL & Sept.-Nov. transaction & 0.25 & 0.43 & 0 & 1 \\
\hline WINTER & Dec.-Feb. transaction & 0.17 & 0.37 & 0 & 1 \\
\hline SPRING & Mar.-May transaction & 0.26 & 0.44 & 0 & 1 \\
\hline BRICK & Brick or stone exterior & 0.48 & 0.50 & 0 & 1 \\
\hline AIR & Central air conditioning & 0.66 & 0.47 & 0 & 1 \\
\hline FULL & Full basement & 0.35 & 0.48 & 0 & 1 \\
\hline NONE & No basement & 0.53 & 0.50 & 0 & 1 \\
\hline OWN & Owner-occupied & 0.89 & 0.31 & 0 & 1 \\
\hline
\end{tabular}


As a prerequisite, the PROC TRANSREG procedure available on SAS (2004) was used to identify the best functional form of Equation 1. The results indicate that the model is best specified with the extended Box-Cox transformation, where the natural logarithm of the dependent and all non-binary independent variables are used in place of the respective linear variables. Therefore, to investigate the research questions, the following model was estimated.

$$
\begin{aligned}
& \ln \text { PRICE }=\alpha+\beta_{1} \ln \text { AGE }+\beta_{2} \ln \text { BED } \\
& +\beta_{3} \operatorname{lnBATH}+\beta_{4} \operatorname{lnCOND}+\beta_{5} \operatorname{lnLOT} \\
& +\beta_{6} \ln \text { FIRE }+\beta_{7} \ln \text { SQFT }+ \\
& \beta_{8} \ln \text { IME }+\beta_{9} \operatorname{lnTIME} 2+\beta_{10} \text { AIR } \\
& +\beta_{11} \text { BRICK }+\beta_{12} \text { FULL }+\beta_{13} \text { NONE } \\
& +\beta_{14} \text { SPRING }+\beta_{15} \text { FALL } \\
& +\beta_{16} \text { WINTER }+\beta_{17} \text { OWN }+ \\
& \sum_{i=18}^{30} \beta_{\mathrm{i}} \text { AREA }+\beta_{31} \text { FLOOD }+\beta_{32} \text { LOMA }+C
\end{aligned}
$$

Where:

$\ln \mathrm{PRICE}=$ The natural logarithm of the transaction price

$\alpha=$ The intercept

$\beta=$ The estimated coefficients

$\ln \mathrm{AGE}=$ The natural logarithm of the structure age in years

$\operatorname{lnBED}=$ The natural logarithm the number of bedrooms

$\operatorname{lnBATH}=$ The natural logarithm of the number of bathrooms

$\operatorname{lnCOND}=$ The natural logarithm of the condition of the property

$\operatorname{lnLOT}=$ The natural logarithm of the number of square feet in the lot,

InFIRE $=$ The natural logarithm of the number of fireplaces

$\operatorname{lnSQFT}=$ The natural logarithm of the number of square feet of living space,

$\operatorname{lnTIME}=$ The natural logarithm of the number of months between the transaction date for the subject property and the oldest transaction date in the sample

$\operatorname{lnTIME} 2=$ The natuaral logarithm of TIME squared

$\mathrm{AIR}=\mathrm{A}$ binary variable equal to 1 if the house had central air conditioning, equal to zero otherwise

$\mathrm{BRICK}=\mathrm{A}$ binary variable equal to 1 if the exterior was either brick or stone, equal to zero otherwise
FULL $=\mathrm{A}$ binary variable equal to 1 if the house had a full basement, equal to zero otherwise

NONE $=$ A binary variable equal to 1 if the house had no basement, equal to zero otherwise,

SPRING $=$ A binary variable equal to 1 if the transaction occurred in March, April or May, equal to zero otherwise

FALL = A binary variable equal to 1 the transaction occurred in September, October or November, equal to zero otherwise

WINTER $=\mathrm{A}$ binary variable equal to 1 if the transaction occurred in December, January or February, equal to zero otherwise

OWN $=\mathrm{A}$ binary variable equal 1 if the property was listed as subject to a homestead exemption in the County Auditor's Office, equal to zero otherwise

AREA $=$ A vector of binary variables each equal to 1 if the parcel was located in a particular neighborhood, equal to zero otherwise

FLOOD $=\mathrm{A}$ binary variable equal to 1 if the parcel is located in the SFHA and no LOMA had been issued prior to the transaction, equal to zero otherwise

LOMA $=$ A binary variable equal to 1 if the parcel is in the SFHA and a LOMA had been issued for the property prior to the transaction, equal to zero otherwise, and

$\epsilon$

$=$ The error term.

The independent variables of particular interest to the present study are FLOOD and LOMA. If either houses in the SFHA with or without a LOMA sold for less than properties outside the SFHA the estimate for FLOOD and LOMA, respectively, should be negative. The other independent variables are included in Equation 1 to control for differences in property characteristics, ownership status (OWN), transaction seasonality (SPRING, FALL, WINTER) and market conditions (TIME, TIME2). Prior studies suggest the estimated coefficient for most of the property characteristic variables should be positive; with $\mathrm{AGE}$ as a notable exception. In the study area, basements offer a place of shelter during severe storms, but also tend to be subject to flooding and other water related problems. Therefore, a priori, the sign on the estimate for FULL and NONE (compared to houses with partial basements; the holdout category) is unknown. Some previous studies have found that houses sell for more during summer months, so the sign of the estimate for FALL, WINTER and SPRING may be negative. Some studies report that individuals 
who intend to reside in a property pay more for houses than those who plan to rent the house to others; so the sign of the estimate for OWN should be positive. The County Auditor rates property condition from "excellent" to "poor." Most houses in Kettering are rated "average." To operationalize these rating, we assigned a rating of average the value 6 and the numerical value ranged from 10 (excellent) to 4 (poor). Finally, we have no reason to anticipate a particular sign of the estimate for any of the AREA variables.

\section{RESULTS AND DISCUSSION}

Examination of Table 4, where the regression results are summarized, will reveal that the data fits the model well. The F statistic is highly significant and the adjusted $\mathrm{R}^{2}$ indicates that the model explains $81.36 \%$ of the variation in the dependent variable. Twenty-four of the 32 independent variables are significant at the $99 \%$ confidence level and two more are significant at the 95\% level. The sign of the estimate for each of the significant control variables has the anticipated sign and the significant estimates appear reasonable in amount. For each of the continuous variables the estimated coefficient is the variable's elasticity (rather than a dollar value). To illustrate, the estimator of 0.048 for BED indicates that houses that had four bedrooms instead of three $(33 \%$ more bedrooms) sold, on average, for $1.58 \%$ more than three bedroom houses, ceteris paribus.

The estimate of each binary variable enables us to calculate the percentage contribution of the variable towards the dependent variable compared to the holdout category for the explanatory variable. To illustrate this point, consider one of our variables of particular interest. The estimate for FLOOD of -0.0287 is significant at the $95 \%$ confidence level. In other words, single-family houses in the SFHA sold for significantly less than similar houses situated outside the SFHA. However, it has been demonstrated that in a semi-log form regression the estimate of a binary variable is biased downward.

Table 4. Regression results

\begin{tabular}{|c|c|c|c|c|}
\hline Variable & Parameter estimate & Standard error & t value & Prob. $>\mathrm{t}$ \\
\hline Intercept & 9.690900 & 0.042800 & 226.32 & $<0.0001$ \\
\hline $\mathrm{AGE}$ & -0.003100 & 0.000200 & -12.65 & $<0.0001$ \\
\hline BED & 0.048000 & 0.004600 & 10.55 & $<0.0001$ \\
\hline BATH & 0.069700 & 0.006200 & 11.28 & $<0.0001$ \\
\hline SQFT & 0.000100 & 0.000005 & 18.70 & $<0.0001$ \\
\hline FIRE & 0.037800 & 0.004700 & 8.11 & $<0.0001$ \\
\hline LOT & 0.000005 & $3.598557 \mathrm{E}-7$ & 14.66 & $<0.0001$ \\
\hline TIME & 0.008200 & 0.000300 & 25.01 & $<0.0001$ \\
\hline TIME2 & -0.000030 & 0.000001 & -21.05 & $<0.0001$ \\
\hline COND & 0.170400 & 0.005000 & 34.31 & $<0.0001$ \\
\hline FALL & -0.014600 & 0.006100 & -2.41 & 0.0159 \\
\hline WINTER & -0.020500 & 0.006900 & -2.99 & 0.0028 \\
\hline SPRING & -0.005300 & 0.006000 & -0.88 & 0.3799 \\
\hline BRICK & -0.006000 & 0.005500 & -1.09 & 0.2753 \\
\hline AIR & 0.031700 & 0.005500 & 5.78 & $<0.0001$ \\
\hline FULL & 0.003800 & 0.008100 & 0.47 & 0.6402 \\
\hline NONE & -0.008200 & 0.008400 & -0.97 & 0.3296 \\
\hline OWN & 0.041600 & 0.007500 & 5.52 & $<0.0001$ \\
\hline AREA1 & -0.121000 & 0.012300 & -9.87 & $<0.0001$ \\
\hline AREA2 & -0.002300 & 0.013800 & -0.16 & 0.8698 \\
\hline AREA3 & -0.102800 & 0.012200 & -8.42 & $<0.0001$ \\
\hline AREA4 & -0.217900 & 0.013400 & -16.30 & $<0.0001$ \\
\hline AREA5 & -0.239500 & 0.014300 & -16.75 & $<0.0001$ \\
\hline AREA6 & -0.115300 & 0.014700 & -7.84 & $<0.0001$ \\
\hline AREA7 & -0.196600 & 0.012700 & -15.46 & $<0.0001$ \\
\hline AREA8 & -0.203600 & 0.013700 & -14.90 & $<0.0001$ \\
\hline AREA9 & -0.115900 & 0.013700 & -8.45 & $<0.0001$ \\
\hline AREA10 & -0.102600 & 0.014500 & - 7.09 & $<0.0001$ \\
\hline AREA11 & -0.094700 & 0.013200 & -7.15 & $<0.0001$ \\
\hline AREA13 & -0.086100 & 0.015900 & -5.41 & $<0.0001$ \\
\hline AREA14 & -0.062000 & 0.015100 & -4.12 & $<0.0001$ \\
\hline FLOOD & -0.028700 & 0.011400 & -2.52 & 0.0119 \\
\hline LOMA & -0.013100 & 0.030600 & -0.43 & 0.6686 \\
\hline
\end{tabular}

$\mathrm{n}=6,233 ; \mathrm{F}$ value $=851.15 ; \operatorname{Pr}>\mathrm{F}<0.0001 ;$ Adjusted $\mathrm{R}^{2}=0.8136$ 
To account for this we follow Kennedy (1981) and compute the percentage change in the price of a house price due to the properties location in the SFHA without a LOMA (g) using Equation 2 where:

$$
g=[\exp (\hat{\beta}-1 / 2 \operatorname{var}(\hat{\beta}))-1] \times 100
$$

and $\hat{\beta}$ is the estimate of a binary variable coefficient and $\operatorname{var}(\hat{\beta})$ is the variance of $\hat{\beta}$. Applying our regression results to Equation 2 indicates that the bias in this case was quite small. On average, SFHA properties without a LOMA sold for $2.84 \%$ less compared to similar properties located outside the SFHA. Finally, the estimate for LOMA is highly insignificant.

\section{CONCLUSION}

One of the objectives of this study was to investigate whether price discounts associated with SFHA property location, routinely reported in other studies, apply to our study area. Our finding in this regard is as anticipated and consistent with previous research; single-family houses without a LOMA in the Kettering, Ohio SFHA sold at a discount compared to similar properties situated outside. However, the size of the average discount in the present study, $2.84 \%$, is low compared to previous studies which reported discounts ranging from 3 to $12 \%$. Previous research offers a possible explanation for the low figure obtained in our sample. Montz (1987) theorized that the impact of SFHA designation on property value may be negatively related to the amount of time since the last flood. Support for this theory has been provided by, among others, Speyrer and Ragas (1991); Bin and Polasky (2004); Kousky (2010) and McKenzie and Levendis (2010) all report that price impacts on single-family houses in a SFHA tend to be larger after a flood occurs compared to beforehand. Therefore, the low discount discovered in the present study may be due to the fact that the last catastrophic flood in the study area occurred approximately a century ago and the last local flood that resulted in a Presidential disaster declaration occurred during the second year of our 23 year study period; 1989 (causing only $\$ 4.3$ million in damage; an inconsequential number compared to the damage caused in other flood studies). Unfortunately, data limitations prevented us from testing whether the size of the discount decreased over the study period, but testing this proposition would be an interesting extension of the research stream.
Another objective of the present study was to determine if the issuance of a LOMA enhanced SFHA property value. It was anticipated that this would occur because property purchasers in this case are not required to secure a flood insurance policy as a prerequisite to obtaining a mortgage loan to finance the acquisition. A LOMA does not increase the elevation of the subject property, but in our sample, it did elevate the property's market value, evidenced by the fact that no price difference was discovered between single-family houses in the SFHA with a LOMA and similar houses outside the SFHA. Property owners may not be the only ones to benefit from the issuance of a LOMA. Local governments whose property tax revenues may increase as the SFHA discount disappears for affected properties should also appreciate LOMAs.

Finally, numerous researchers have observed that the discount attributable to SFHA location consists of two components: (1) the present value of the required flood insurance policy premiums and (2) uninsurable costs. Because a LOMA removes the insurance requirement any price discount on LOMA properties would be attributable solely to uninsurable costs and subtracting any significant discount for properties with a LOMA from the discount that applies to SFHA properties without a LOMA will indicate the portion of the larger discount that is attributable to the flood insurance premiums. In our sample, no significant uninsurable costs were detected. This process could be employed in any market with enough transactions to provide statistically reliable results and applying the process to other markets might be an informative exercise.

\section{REFERENCES}

Bin, O. and S. Polasky, 2004. Effects of flood hazards on property values: Evidence before and after hurricane floyd. Land Econom., 80: 490-500. DOI: $10.2307 / 3655805$

Bin, O., T. Crawford, J.B. Kruse and C.E. Landry, 2008. Viewscapes and flood hazard: Coastal housing market response to amenities and risk. Land Econom., 84: 434-448. DOI: 10.3368/le.84.3.434

Harrison, D.M., G.T. Smersh and A.L. Schwartz, 2001. Environmental determinants of housing prices: The impact of flood zone status. J. Real Estate Res., 21: 3-20.

Hooker, C., 2004 Montgomery county natural hazard mitigation draft plan. Wright State University, Dayton, Ohio. 
Kennedy, P., 1981. Estimation with correctly interpreted dummy variables in semi-logarithmic equations. Am. Econ. Rev., 71: 4-801.

Kousky, C., 2010. Learning from extreme events: Risk perceptions after the flood. Land Econ., 86: 395-422.

MacDonald, D.N., H.L. White, P.M. Taube and W.L. Huth, 1990. Flood hazard pricing and insurance premium differentials: Evidence from the housing market. J. Risk Insurance, 57: 654-663. DOI: $10.2307 / 252950$

McKenzie, R. and J. Levendis, 2010. Flood hazards and urban housing markets: The effects of Katrina on new orleans. J. Real Estate Finance Econ., 40: 6276. DOI: $10.1007 / \mathrm{s} 11146-008-9141-3$
Montz, B.E., 1987. Floodplain delineation and housing submarkets: Two case studies. Professional Geograp., 39: 59-61. DOI: 10.1111/j.00330124.1987.00059.x

Perry, C.A., 2000. Significant Floods in the United States during the 20th Century: USGS Measures a Century of Floods. 1st Edn., Geological Survey, Reston, pp: 4.

SAS, 2004. SAS OnlineDoc ${ }^{\circledR}$ 9.1.3. SAS Institute, Cary, NC.

Speyrer, J.F. and W.R. Ragas, 1991. Housing prices and flood risk: An examination using spline regression. J. Real. Estate Finance Econ., 4: 395-407. DOI: 10.1007/BF00219506 